Pesq. Vet. Bras. 36(6):520-525, junho 2016

DOI: $10.1590 / \mathrm{S} 0100-736 \mathrm{X} 2016000600010$

Artigo de Revisão

\title{
Membrana amniótica: fonte alternativa de células-tronco mesenquimais em diversas espécies animais ${ }^{1}$
}

\author{
Thalita Faita ${ }^{2}$, Verônica N. Silva², William R. Sattin ${ }^{2}$, Alessandra O. Pinheiro ${ }^{2}$ \\ e Carlos E. Ambrósio ${ }^{2 *}$
}

\begin{abstract}
Faita T., Silva V.N., Sattin W.R., Pinheiro A.O. \& Ambrósio C.E. 2016. [Amniotic membrane: alternative source of mesenchymal stromal cells in several animals species.] Membrana amniótica: fonte alternativa de células-tronco mesenquimais em diversas espécies animais. Pesquisa Veterinária Brasileira 36(6):520-525. Departamento de Medicina Veterinária, Universidade de São Paulo, Rua Duque de Caxias Norte 225, Campus Fernando Costa, USP, Pirassununga, SP 13635-900, Brazil. E-maol: ceambrosio@usp.br

The increasing interest for the use of stem cells in regenerative medicine, is based on their self-renewal capacity, tissue repair and immunomodulation. The therapy with stem cells is a science in formation considered a promising therapeutic alternative for the treatment of various degenerative, hereditary and inflammatory disorders. The search for alternative sources of stem cells of easy obtention and isolation has led to the study of various tissues, includng embryonic attachments such as the amniotic membrane. However for effective therapeutic application are needed studies of the characteristics in vitro and preclinical and clinical trials. Thus, the aim of this study was a literature review regarding the characterization and clinical application of stem cells from the amniotic membrane in several domestic animal species.
\end{abstract}

INDEX TERMS: Stem cells, amnion, mesenchymal cells.

RESUMO-- 0 crescente interesse do uso de células-tronco (CTs) na medicina regenerativa, estão baseadas na sua capacidade de autorrenovação, reparação tecidual e imunomodulação. A terapia utilizando células-tronco é uma ciência em formação considerada uma alternativa terapêutica promissora no tratamento de diversas patologias degenerativas, hereditárias e inflamatórias. A busca por fontes alternativas de CTs que possuam características como fácil obtenção e isolamento, tem levado ao estudo dos mais variados tecidos, onde se inclui os anexos embrionários como a membrana amniótica. Porém, para sua efetiva aplicação terapêutica são necessários estudos de suas características "in vitro", além de testes pré-clínicos e clínicos. Com isso, o objetivo deste trabalho é realizar uma revisão bibliográfica sobre a caracterização e aplicação clínica das células-tronco da membrana amniótica em diversas espécies de animais domésticos.

TERMOS DE INDEXAÇÃO: Células-tronco, âmnio, células mesenquimais.

\footnotetext{
${ }^{1}$ Recebido em 12 de fevereiro de 2016.

Aceito em 15 de março de 2016.

${ }^{2}$ Departamento de Medicina Veterinária (ZMV), Universidade de São Paulo (USP), Rua Duque de Caxias Norte 225, Campus Fernando Costa, Pirassununga, SP 13635-900, Brasil. *Autor para correspondência: ceambrosio@usp.br
}

\section{INTRODUÇÃo}

Com o avanço dos métodos de diagnóstico em doenças crônicas e degenerativas, houve um consequente crescimento nos estudos que visam terapias e tratamentos inovadores. Dentro desse novo contexto, a utilização das células-tronco (CTs) tem sido alvo de grande interesse da comunidade científica e uma possível esperança para melhoria da qualidade de vida para as mais diversas afecções de diversas espécies (Nardi \& Meirelles 2006).

0 interesse no uso de CTs em novas terapias é baseado nas características que envolvem a imunomodulação e reparação tecidual. As CTs podem ser classificadas em células-tronco embrionárias (CTEs) e células-tronco somáticas (CTSs), segundo sua origem. As CTEs são derivadas da massa celular interna do blastocisto. Por sua vez, as CTSs são obtidas a partir de tecidos adultos, e podem ser classificadas como CTSs hematopoiéticas e CTSs mesenquimais (Del Carlo et al. 2008). Considerando os diferentes tipos de CTs, as células-tronco mesenquimais (MSCs) das mais diferentes espécies animais têm sido alvo de estudos devido suas características, como a plasticidade, auto-renovação e diferenciação em distintas linhagens celulares. (Mendelow et al. 1980, Pittenger et al. 1999, Pountos \& Giannoudis 2005). Essas células de alto poder regenerativo, vêm 
sendo utilizadas na medicina reparativa, objetivando-se o aprimoramento e desenvolvimento de técnicas capazes de utilizar seu potencial de regeneração de forma segura para diferentes tipos de injúria tecidual (Watt \& Hogan 2000, Lemichka 2005).

Devido às barreiras técnicas e éticas envolvidas na utilização de células-tronco embrionárias, busca-se por fontes alternativas de tecidos somáticos, sendo os anexos fetais como o fluído amniótico, cordão umbilical e membrana amniótica (Zucconi et al. 2010) fontes promissoras de MSCs com grande potencial de aplicação na medicina regenerativa. Em cultura, as células-tronco derivadas de membrana amniótica e de líquido amniótico humano apresentam características semelhantes relacionadas com a expressão de marcadores de MSCs, tais como alta plasticidade, marcação imunofenotípica positiva para marcadores mesenquimais como CD73, C90 e CD105, potencial de pluripotência, diferenciação em diversas linhagens celulares, além de propriedade angiogênicas, citoprotetoras, imunomoduladoras e anti-teratogênicas. (Favaron et al. 2015, Martinelli et al. 2016). Quanto às diferenças entre a membrana amniótica e o líquido amniótico podemos citar a diversidade citológica identificada no líquido amniótico devido a sua estreita relação com o feto. No líquido amniótico podemos identificar a presença de células epiteliais, células da mucosa respiratória e digestiva, camadas genito-urinário e outros elementos que entram em contato com este líquido (Favaron et al. 2015).

\section{Células-tronco: utilização, características e classificações}

Desde a década de 60, as CTs são utilizadas na medicina humana em transplantes de medula óssea e atualmente existem diversas pesquisas e hipóteses relacionadas à suas capacidades terapêuticas (Gavaghan 2001). Seu uso foi baseado em estudos antigos das células hematopoiéticas, que ganharam destaque ao se descobrir o poder regenerativo do transplante de medula em ratos (Ford et al. 1956). Alguns estudos demonstram novos potencias terapêuticos como no tratamento de doenças neurodegenerativas e metabólicas humanas, como a Doença de Parkinson e a Diabetes Mellitus Tipo 1 (Gavaghan 2001).

As células-tronco possuem como características a capacidade de diferenciação celular, o que as permitem originar os mais diversos tecidos a partir de resposta a estímulos externos, gerando linhagens celulares mais especializadas como tecido muscular esquelético, ósseo, cartilaginoso e adiposo (Souza et al. 2003, Pereira 2008, Yarak \& Okamoto, 2010). Além disso, possuem o poder de auto-renovação e diferenciação ilimitado (Watt \& Hogan 2000) característica que pode estar associada à presença da enzima telomerase durante a replicação celular (Chiu et al. 1996, Odorico et al. 2001). Elas podem ser encontradas tanto no tecido embrionário como no extra-embrionário, e podem permanecer quiescentes até a fase adulta, se diferenciando conforme a necessidade de substituição e reparação (Souza et al. 2003). Essas características justificam o grande e crescente interesse em seu estudo, sendo o mecanismo regenerativo dessas células já utilizado em situações de lesões ou injúria. 0 que se busca, portanto, é aprimorar as técnicas envolvidas no controle da diferenciação celular (Lemichka 2005).
As células-tronco podem ser classificadas quanto sua potencialidade em totipotentes, pluripotentes, multipotentes e unipotentes. As totipotentes apresentam como característica a capacidade de gerar todos os tecidos do organismo e do folheto embrionário; as classificadas como pluripotentes apresentam a capacidade de gerar todas as linhagens celulares, porém não originam células da membrana extra embrionário; por sua vez, as multipotentes originam células do próprio tecido isolado e diversas células de tecidos somáticos (Souza et al. 2003) e as células-tronco unipotentes originam apenas um tipo celular do folheto (Yarak \& Okamoto 2010).

Outra classificação é realizada de acordo com a sua origem em células-tronco embrionárias (CTEs) e as células-tronco somáticas (CTSs). As CTEs são obtidas da massa interna do blastocisto. As células-tronco somáticas são consideradas células multipotentes que possuem potencial de se diferenciarem em múltiplas linhagens celulares, sendo classificadas em células hematopoiéticas e mesenquimais. São consideradas relevantes no uso da terapia celular devido sua facilidade de isolamento de quase todos os tecidos adultos, cultivo e formação de banco de células (Dominici et al. 2006, Del Carlo et al. 2008, Nery et al. 2013).

As Células-tronco mesenquimais (MSCs) são células multipotentes, que durante muitos anos foram obtidas majoritariamente da medula óssea. Porém na atualidade, já são isoladas de diversos tecidos adultos, como o adiposo, renal, pancreático e muscular (Meirelles et al. 2006), e fetais como o âmnio, cordão umbilical e líquido amniótico (Miglino et al. 2006, Cremonesi 2011). Por terem algumas características desejáveis como sua aderência ao plástico que facilita seu cultivo "in vitro", sua alta plasticidade, uma vez que geram tanto tecidos mesodermais como não-mesodermais (Zago \& Covas 2004), e permanecerem com as características proliferativas e de auto renovação mesmo após o isolamento (Brooke et al. 2007), tem sido utilizada como uma fonte segura para estudos e aplicação terapêutica das células-tronco, mesmo quando inoculadas em terapias celulares em humanos (Horwitz et al. 2006).

\section{Membrana amniótica: estrutura, morfologia e funções}

Animais vivíparos completam seu desenvolvimento embrionário dentro do útero, sendo esse período chamado de prenhez, o qual está intimamente relacionado com a nutrição e desenvolvimento do feto. A prenhez ou a gestação corresponde ao período que ocorre desde o acasalamento até o momento do parto, podendo ser influenciada por diversos fatores gerais, tais como: fatores maternos, fetais, genéticos e ambientais, além das diferenças relacionada com cada espécie (Hafez et al. 2004).

A placenta é a justaposição das membranas fetais com o endométrio, que permite as trocas fisiológicas entre a mãe e o feto, os quais são ligados pelo cordão umbilical. 0 tamanho e a função da placenta mudam continuamente durante a prenhez, sendo sua morfogênese intimamente relacionada às membranas extraembrionárias (Hafez et al. 2004).

As membranas fetais participam da formação da placenta de forma associada ou isolada, sendo o âmnio, córion, alantoide e saco vitelino as quatro membranas fetais con- 
sideradas comuns na maioria das espécies vivíparas. Essas membranas fetais originam os três tipos de classificação de placentas, que são diferenciadas pelas membranas fetais envolvidas (coriônica, corioalantóide e vitelina). As membranas fetais corioalantóide originam-se da fusão do alantoide com o córion, sendo esta membrana característica de todos os animais domésticos (Hafez et al. 2004, Bertassoli et al. 2013)

A membrana amniótica já foi utilizada em diversos tipos de terapias em animais e humanos, através do tratamento de lesões de pele secundárias a queimaduras químicas, lesões penfigóides cicatriciais, síndrome de Stevens Johnson, úlceras corneanas persistentes, dentre outras. Tem-se demonstrado características antiadesivas, antibacterianas, imunomoduladoras, e de proteção da ferida, além de facilitar a adesão e migração de células epiteliais basais melhorando a restauração do fenótipo epitelial (Moreira et al. 2000).

0 âmnio é a membrana extraembrionária mais interna que envolve o feto e delimita a cavidade amniótica repleta do fluído amniótico proporcionando um nicho para o desenvolvimento do concepto e conferindo proteção e resistência ao impacto (Figura 1 e Figura 2). Geralmente o âmnio é descartado após o parto sendo considerada uma fonte alternativa de MSCs que possuem a vantagem de estar isentas de barreiras éticas (Pereira et al. 2011, Cardoso et al. 2014).

Essa membrana é constituída por uma camada epitelial de células cubóides (AECs) que delineiam a camada interna da cavidade amniótica, denominada ectoderma amniótico. Estas células derivam do epiblasto (também denominadas amnioblastos) antes da gastrulação e se diferenciam em AECs. Logo a seguir do ectoderma amniótico encontra-se uma fina camada da mesoderme adjacente ao forro mesodérmico do córion. As células amnióticas mesenquimais (AMCs) encontram-se aleatoriamente distribuídos na matriz extracelular, tendo uma origem mesodérmica extraembrionária. São ricas em colágeno e laminina e apresentam aspecto fibroblastóide (Chang et al. 2010, Pereira et al. 2011).

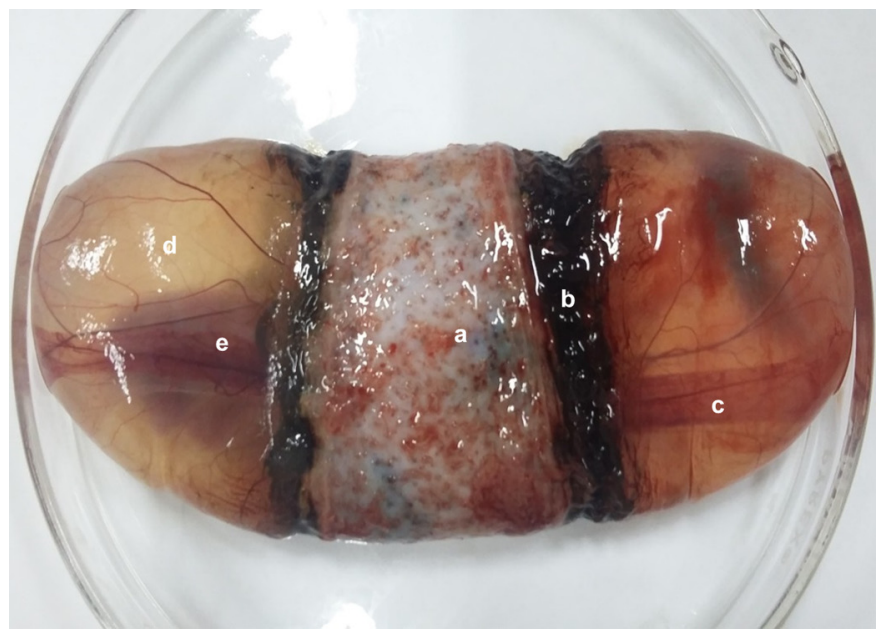

Fig.1. Feto canino de 35 dias de idade gestacional envolto pelas membranas fetais: (a) cinta placentária, (b) hematoma marginal, (c) saco vitelino (d) membrana corioalantóide com presença de vascularização e preenchida por líquido alantóico (e) feto canino. Fonte: Pinheiro A.O. (2016).

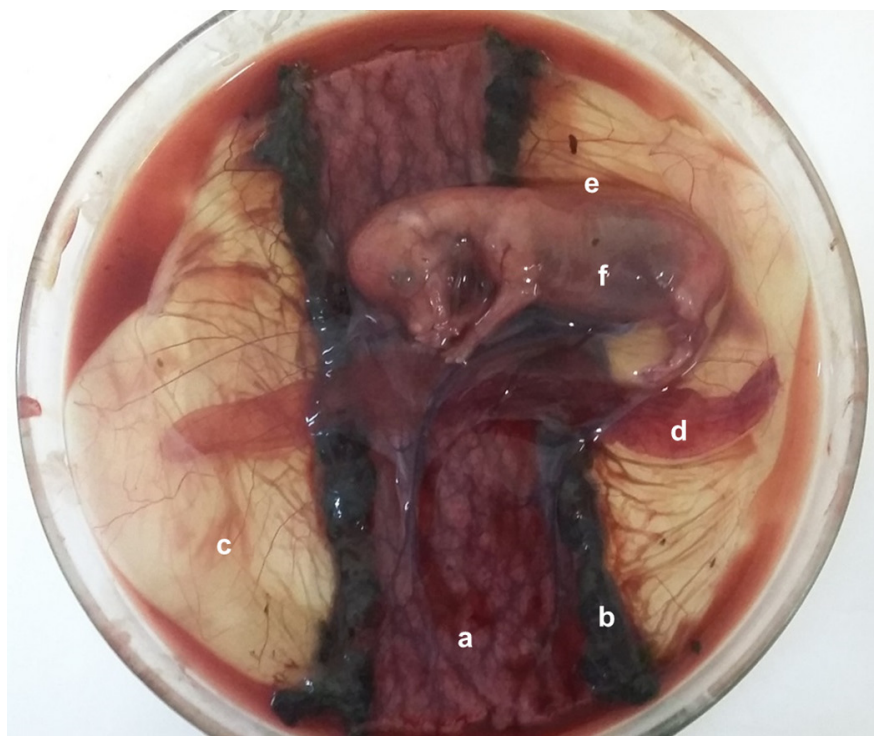

Fig.2. Feto canino de 35 dias de idade gestacional (a) cinta placentária, (b) hematoma marginal, (c) membrana corioalantóide vascularizada, (d) saco vitelino, (e) membrana alantoâmnio e (f) feto canino de 35 dias de idade gestacional. Fonte: Pinheiro A.O. (2016).

\section{CTs de membrana amniótica canina}

0 âmnio canino se apresenta como uma fonte promissora de MSCs, com alto potencial para utilização em terapia celular, sendo que estas células podem ser criopreservadas e propagadas em cultivo com várias passagens sem alteração de suas qualidades funcionais e sem que haja redução de suas características imunofenotípicas (Cardoso et al. 2014). Células-tronco multipotentes foram isoladas e identificadas em membranas amnióticas de cães, caracterizando o âmnio como uma rica fonte de células-tronco, com possíveis utilizações em terapia celular na medicina veterinária regenerativa (Park et al. 2012). MSCs coletadas do fluído amniótico de fetos caninos no terceiro trimestre gestacional apresentaram diferenciação in vitro em linhagens celulares condrogênicas, adipogênicas, osteogênicas e neurogênicas, demonstrando potencial progenitor (Fernandes et al. 2012). Estas células também demonstram estabilidade cromossomal e possível utilização como modelo de estudo de células-tronco, e apresentam aplicação em programas terapêuticos (Filioli et al. 2011).

\section{CTs de membrana amniótica felina}

Estudos preliminares relatam que fluídos e membranas fetais podem se apresentar como uma fonte alternativa de MSCs em espécies felinas (Iacono et al. 2012).

A membrana amniótica de felinos domésticos possui células mesenquimais com morfologia e fenótipo típicos de células progenitoras, apresentando a capacidade de propagação em cultivo celular sem que haja perda de suas qualidades funcionais, e com possível diferenciação em múltiplas linhagens específicas, sendo relatadas a diferenciação em linhagens osteogênicas, condrogênicas e adipogênicas (Cardoso et al. 2014).

Além disso, as MSCs isoladas da membrana amniótica de gatos domésticos não apresentam carcinogenicidade, 
fato concluído a partir da injeção de células mesenquimais indiferenciadas em ratos imunodeficientes e com verificação da não formação de teratomas após quatro semanas (Vidane et al. 2014). Dessa forma, a membrana amniótica de felinos domésticos se apresenta como uma importante fonte de células-tronco mesenquimais, com aplicações na medicina regenerativa, em especial para reposição de tecidos ou células em casos crônicos e em doenças degenerativas (Filioli et al. 2011).

\section{CTs de membrana amniótica equina}

Em equinos a fonte de MSCs mais utilizada é a medula óssea, porém devido à diminuição dessas células com o avanço da idade do animal, e ao declínio de seu potencial terapêutico com o tempo, busca-se fontes alternativas, sendo que as células provenientes de anexos fetais têm ganhado destaque (De Vita et al. 2012).

Células progenitoras isoladas da membrana amniótica equina apresentam morfologia epitelial poliglonal. Estas células são caracterizadas por alta plasticidade e possibilitam diferenciação in vitro em linhagens osteogênicas, adipogênicas, condrogênicas e neurogênicas. Além disso, permitem congelamento e recuperação sem perda funcional morfológica. Em estudo in vivo, essas células injetadas em três equinos que apresentavam lesões tendíneas, levaram a uma rápida redução da lesão, avaliada por meio de acompanhamento ultrassonográfico. Dessa forma, essas células são importante recurso para terapia celular (Lange-Consiglio et al. 2011).

\section{CTs de membrana amniótica bovina e bubalina}

Em búfalos, estudos demonstraram que MSCs derivadas do âmnio podem ser isoladas e propagadas em cultivo com várias passagens, podendo ter aplicações em diversas áreas como reprodução assistida, desenvolvimento biológico e medicina regenerativa (Yadav et al. 2011, Mann et al. 2013). Além disso, foi relatado que células derivadas da membrana amniótica expressam pluripotência e marcadores de células-tronco mesenquimais, e são propensos a se diferenciarem em células de linhagem mesenquimal com diferenciação in vitro (Ghosh et al. 2015).

Em bovinos, âmnio e fluído amniótico são fontes de MSCs amplamente utilizadas, sendo coletadas de maneira não invasiva e com baixo custo. Estas células se apresentam como promissoras no tratamento de doenças, especialmente devido à sua imunogenicidade reduzida e alto potencial anti-inflamatório. Estudos demonstraram que quando adequadamente induzidas, estas células podem se diferenciar em linhagens ectodermais e mesodermais (Corradetti et al. 2013).

\section{CTs de membrana amniótica ovina e caprina}

Em ovinos, as MSCs derivadas do fluído ou da membrana amniótica apresentaram proliferação, pluripotência e se diferenciaram in vitro em linhagens osteogênicas e de músculo liso. Assim, estas células caracterizam uma fonte alternativa de MSCs, de fácil coleta e cultivo in vitro. Podem ser utilizadas em estudos pré-clínicos para o desenvolvimento de futuras terapias aplicadas à humanos (Mauro et al. 2010).
MSCs derivadas do fluido amniótico de caprinos demonstram alto nível de proliferação in vitro, e em condições apropriadas se diferenciam em linhagens adipogênicas, osteogênicas e condrogênicas, com acentuada propriedade de pluripotência, representando uma fonte promissora para múltiplas terapias regenerativas (Pratheesh et al. 2013).

\section{CTs de membrana amniótica suína}

0 âmnio suíno contém células primitivas únicas, com facilidade de coleta e propagação in vitro, sendo este tecido um candidato atrativo como fonte de células-tronco para pesquisas biomédicas e biotecnológicas (Lange-Consiglio et al. 2014).

As células mesenquimais isoladas e caracterizadas do fluido amniótico suíno são capazes de se diferenciarem in vitro em neurócitos, adipócitos e cardiomiócitos. Além disso, não apresentam potencial teratogênico, demonstrando assim uma excelente fonte alternativa de MSCs com potencial de utilização em medicina regenerativa (Chen et al. 2011).

\section{Perspectivas de terapias celulares em animais}

A aplicação de MSCs obtidas a partir do âmnio ou fluído amniótico na medicina regenerativa requer estudos extensivos quanto à sua aplicação clínica (Rosner et al. 2012). Para a efetiva aplicação em terapias celulares em modelos in vivo, são necessários estudos quanto à caracterização dessas células por meio de marcadores funcionais e fenotípicos específicos, além de estudos experimentais pré-clínicos e clínicos, para entendimento de aspectos quanto ao seu mecanismo de ação (De Bakker et al. 2013).

\section{CONCLUSÕES}

As MSCs obtidas a partir do âmnio ou fluído amniótico apresentam características desejáveis para a aplicação em terapias celulares.

Tais características incluem facilidade de coleta, possibilidade de criopreservação; propagação em cultivo sem perda de qualidade funcional, morfológica ou fenotípica; alta plasticidade; diferenciação em diferentes linhagens celulares; estabilidade cromossomal; não apresentação de carcinogenicidade; imunogenicidade reduzida e alto potencial anti-inflamatório.

Dessa forma, essas células possuem aplicação promissora e potencial especialmente em medicina regenerativa, pesquisas biomédicas e bioctecnológicas. Porém, para sua efetiva aplicação terapêutica são necessários estudos pré-clínicos e clínicos, com determinação de suas características e mecanismo de ação.

\section{REFERÊNCIAS}

Bertassoli B.M., Oliveira F.D., Oliveira D.M. \& Rossi C.N. 2013. Células-tronco mesenquimais de cães e gatos - uma revisão bibliográfica. REDVET, Revta Eletron. Vet. 14(9):1-17.

Brooke G., Cook M., Blair C., Han R., Heazlewood C., Jones B., Kambouris M., Kollar K., McTaggart S., Pelekanos R., Rice A., Rossetti T. \& Atkinson K. 2007. Therapeutic applications of mesenchymal stromal cells. Semin. Cel. Dev. Biol. 18:846-858.

Cardoso M.T., Vidane A.S., Martins D.S., Ambrósio C.E. 2014. A melhor 
fonte de células-tronco: o âmnion do cão e do gato. Acta Vet. Brasilica 8(2):269-274.

Chang Y.J., Hwang S.M., Tseng C.P., Cheng F.C., Huang S.H., Hsu L.F., Hsu L.W. \& Tsai M.S. 2010. Isolation of mesenchymal stem cells with neurogenic potential from the mesoderm of the amniotic membrane. Cells Tis. Org. 192(2):93-105.

Chen J., Lu Z., Cheng D., Peng S. \& Wang H. 2011. Isolation and characterization of porcine amniotic fluid-derived multipotent stem cells. Plos One. 6(5):e19964.

Chiu C.P., Dragowska W., Kim N.W., Vaziri H., Yui J., Thomas T.E., Harley C.B. \& Lansdorp P.M. 1996. Differential Expression of Telomerase Activity in Hematopoietic Progenitors from Adult Human Bone Marrow. Stem Cells. 14(2):239-248.

Corradetti B., Meucci A., Bizzaro D., Cremonesi F. \& Consiglio A.L. 2013. Mesenchymal stem cells from amnio and amniotic fluid in the bovine. Reproduction 145:351-400.

Cremonesi F., Corradetti B. \& Consiglio A.L. 2011. Fetal adnexa derived stem cells from domestic animals: progress and perspectives. Theriogenoly 75(8):1400-1415.

De Bakker E., Van Ryssen B., De Schauwer C. \& Meyer E. 2013. Canine mesenchymal stem cells: State of the art, perspectives as therapy for dogs and as a model for man. Vet Quart. 33(4):225-233.

De Vita B., Campos L.L., Listoni A.J., Maia L., Freitas N.P.P., Alvarenga F.L. \& Prestes N.C. 2012. Anexos fetais: uma fonte alternativa de células-tronco mesenquimais para a medicina veterinária equina. Vet. Zootec. 19(1):822.

Del Carlo R.J., Monteiro B.S. \& Argôlo Neto M. 2008. Células-tronco e fatores de crescimento na reparação tecidual. Ciênc. Vet. Tróp. 11(1):167169.

Dominici M., Le Blanc K., Mueller I., Slaper-Cortenbach I., Marini F.C., Krause D.S., Deans R.J., Keating A., Prockop D.J. \& Horwitz E.M. 2006. Minimal criteria for defining multipotent mesenchymal stromal cells. The international society for cellular therapy positions statement. Cytotherapy 8(4):315-317.

Favaron P.O., Carvalho R.C., Borghesi J., Anunciação A.R. \& Miglino M.A. 2015. Theamniotic membrane: development and potential applications: a review. Reprod. Domest. Anim. 50(6):881-892.

Fernandes R.A., Wenceslau CV., Reginato A.L., Kerkis I. \& Miglino M.A. 2012. Derivation and characterization of progenitor stem cells from canine allantois and amniotic fluids at the third trimester of gestation. Placenta 33(8):640-644.

Filioli U.M., Valentini L., Lange-Consiglio A., Caira M., Guaricci A.C., L'abbate A., Catacchio C.R., Ventura M., Cremonesi F. \& Dell'aquila M.E. 2011. Isolation, proliferation, cytogenetic, and molecular characterization and in vitro differentiation potency of canine stem cells from foetal adnexa: A comparative study of amniotic fluid, amnio, and umbilical cord matrix. Mol. Reprod. Dev. 78(5):361-373.

Ford C.E., Hamerton J.l., Barnes D.W.H. \& Loutit J.F. 1956. Cytological identification of radiation-chimaeras. Nature 177:452-454.

Gavaghan H., Bridge H. \& Yorkshire W. 2001. News features: the promise of stem cells.Bull. World Health. Org. 79(8):800-801.

Ghosh K., Kumar R., Singh J., Gahlawat S.K., Kumar D., Selokar N.L., Yadav S.P., Gulati B.R. \& Yadav P.S. 2015. Buffalo (Bubalus bubalis) term amniotic-membrane-derivedcellsexhibited mesenchymalstemcells characteristics in vitro. In Vitro Cell Dev. Biol. Anim. 51(9):951-921.

Hafez B. \& Hafez E.S.E. 2004. Reprodução Animal. 7ạ ed. Manole, São Paulo.

Horwitz E.M., Andreef M. \& Frassoni F. 2006. Mesenchymal stromal cells. Curr. Opin. Hematol. 13(6):419-425.

Iacono E., Cunto M., Zambelli D., Ricci F., Tazzari P.L. \& Merlo B. 2012. Could fetal fluid and membranes be an alternative source for mesenchymal stem cells (MSCs) in the feline species?: a preliminary study. Vet. Res. Commun. 36:107-118.

Lange-Consiglio A., Corradetti B., Bizarro D., Maggati M., Ressel L., Tassan S., Parolini O. \& Cremonesi F. 2011. Characterization and potential applications of progenitor-like cells isolated from horse amniotic membrane. J. Tissue Eng. Regen. Med. 6(8):622-35.
Lange-Consiglio A., Corradetti B., Notarstefano V., Marini M.G., Perrini C., Bizarro D. \& Cremonesi F. 2014. Porcine amnio: a source of epithelial stem cells. Reprod. Fertil. Dev. 27(1):252-252.

Lemichka I.R. 2005. Stem cell biology: a view toward the future. Ann. N.Y. Acad. Sci. 1044:132-138.

Mann A., Yadav R.P., Singh J., Kumar D., Singh B. \& Yadav P.S. 2013. Culture, characterization and differentiation of cells from buffalo (Bubalus bubalis) âmnio. Cytotechnology 65:23-30.

Martinelli D., Pereira R.C., Mogni M., Benelli R., Mastrogiacomo M., Coviello D., Cancedda R. \& Gentili C. 2016. A humanized system to expand in vitro amniotic fluid-derived stem cells intended for clinical application. Cytotherapy 18(3):438-451.

Mauro A., Turriani M., Ioannoni A., Russo V., Martelli A., Di Giancinto O., Nardinocchi D. \& Berardinelli P. 2010. Isolation, characterization, and in vitro differentiation of ovine amniotic stem cells. Vet. Res. Commun. 34:825-828.

Meirelles L.S., Chagastelles P.C. \& Nardi N.B. 2006. Mesenchymal stem cells reside in virtually all post-natal organs and tissues. J. Cell Sci. 119:22042213.

Mendelow B.D., La Hunt G.M., Kat J. \& Matz J. 1980. Characterization of bone marrow stromal cells in suspension and monolayer cultures. Brit. J. Haematol. 46:15-22.

Miglino M.A., Ambrosio C.E., Martins D.S., Pfarrer C. \& Leiser R. 2006. The carnivore pregnancy: the development of the embryo and fetal membranes. Theriogenology 66:1699-1702.

Moreira H. \& Oliveira C.S.O. 2000. Transplante de membrana amniótica. Arq. Bras. Oftalmol. 63(4):303-305.

Nardi N.B. \& Meirelles L.S. 2006. Mesenchymal stem cells: isolation, in vitro expansion and characterization. Handb. Exp. Pharmacol. 174:249282.

Nery A.A., Nascimento I.C., Glaser T., Bossaneze V., Krieger J.E. \& Ulrich H. 2013. Human mesenchymal stem cells: From immunophenotyping by flow cytometry to clinical applications. Int. Soc. Adv. Cytol. 83:48-61.

Odorico J.S., Kaufman D.S. \& Thomson J.A. 2001. Multilineage differentiation from human embryonic stem cell lines. Stem Cells Dayton. 19:193204.

Park S.B., Seo M.S., Kim H.S. \& Kang K.S. 2012. Isolation and characterization of canine amniotic membrane-derived multipotent stem cells. PLoS One 7(9):e44693.

Pereira L.V.A. 2008. Importância do uso de células-tronco para a saúde pública. Ciênc. Saúde Coletiva 13(1):7-14.

Pereira P.N.G., Dobreva M.P., Graham L., Huylebroeck D., Lawson K.A. \& Zwijsen A.N. 2011. Âmnio formation in the mouse embryo: the single amniochorionic fold model. BMC Develop. Biol. 11(48):1-13.

Pittenger M.F., Mackay A.M., Beck A.D., Jaiswal R.K., Douglas R., Mosca J.D., Moorman M.A., Simonetti D.W., Craig S. \& Marshak D.R. 1999. Multilineage potential of adult human mesenchymal stem cells. Science 284(541):143-147.

Pountos I. \& Giannoudis P.V. 2005. Biology of mesenchymal stem cells.Injury 36(3):8-12.

Pratheesh M.D., Gade N.E., Katiyar A.N., Dubey P.K., Sharma B., Saikumar G. \& Amarpal G.T. 2013. Isolation, culture and characterization of caprine mesenchymal stem cells derived from amniotic fluid. Res. Vet. Sci. 94(2): 313-319.

Rosner M., Schipany K., Shanmugasundaram B., Lubec G. \& Hengstschl M. 2012. Amniotic fluid stem cells: future perspectives. Stem Cells Int. 2012(2012):1-6.

Souza V.F., Lima L.M.C., Reis S.R.A., Ramalho L.M.P. \& Santos J.N. 2003. Células-tronco: uma breve revisão. Revta Ciênc. Méd. Biol. 2(2):251-256.

Vidane A.S., Souza A.F., Sampaio R.V., Bressan F.F., Pieri N.C., Martins D.S., Meirelles F.V., Miglino M.A. \& Ambrósio C.E. 2014. Cat amniotic membrane multipotent cells are nontumorigenic and are safe for use in cell transplantation. Stem Cells Cloning 7:71-78.

Watt F.M. \& Hogan B.L.M. 2000. Out of eden: stem cells and their niches. Science 287:1427-1430. 
Yadav P.S., Mann V.S., Yashveer S., Sharma R.K. \& Singh I. 2011. Buffalo (Bubalus bubalis) term amniotic-membrane-derivedcellsexhibited mesenchymalstemcells characteristics in vitro. Reprod. Domest. Anim. 46:705-711.

Yarak S. \& Okamoto O.K. 2010. Células-tronco derivadas de tecido adiposo humano: desafios atuais e perspectivas clínicas. Anais Bras. Dermatol. 85(5):647-656.
Zago M.A. \& Covas D.T. 2004. Pesquisas com células-tronco: aspectos científicos, éticos e sociais. Inst. Fernando Henrique Cardoso 1:1-20.

Zucconi E., Vieira N.M., Bueno D.F., Secco M., Jazedje T., Ambrosio C.E., Passos-Bueno M.R., Miglino M.A. \& Zatz M. 2010. Mesenchymal stem cells derived from canine umbilical cord vein: a novel source for cell therapy studies. Stem Cells Develop. 19(3):395-402. 